\title{
LOS CONTRATOS DE PRODUCCIÓN EN EL NOROESTE DE MÉXICO: EL VALLE DE MEXICALI A FINES DE LA DÉCADA DE LOS OCHENTA
}

\author{
Por \\ Martha Stamatis Maldonado*
}

\begin{abstract}
RESUMEN
El objetivo del presente trabajo es analizar la presencia de contratos de producción entre los productores de hortalizas de exportación en el valle de Mexicali y el capital estadounidense. A partir de una caracterización de los productores de hortalizas en el valle de Mexicali, se describe la forma básica que asumen las relaciones de financiamiento y de comercialización con las compañías distribuidoras, y se analizan esas relaciones en el contexto de la producción de hortalizas de exportación en el noroeste de México.
\end{abstract}

\begin{abstract}
The objective of the present work is to analize the presence of production contracts established among the producers of garden produce for exportation in the Mexicali Valley and American investors. From the caracterization of the producers of garden produce in the Mexicali Valley, it is described the basic form taken by the relationships of financial and comercialization with the distribution companies, and those relations are analized in the context of the production of garden produce for exportation in the Northwest of Mexico.
\end{abstract}

\section{A MANERA DE INTRODUCCIÓN}

El desarrollo de la agricultura mexicana ha estado condicionado, en gran medida, por la presencia de capital extranjero, el cual ha impactado en particular la evolución del patrón de cultivos y la composición y dinámica de las exportaciones agrícolas. Debido a una serie de factores internos y externos, actualmente esa inversion extranjera (IE) se localiza exclusivamente en la producción de hortalizas.

En la producción de hortalizas con IE podemos distinguir dos sectores, uno destinado al procesamiento industrial y el otro al consumo fresco. En ambos casos, la IE estadounidense ha participado otorgando algún tipo de financiamiento al productor mexicano a cambio del compromiso

\footnotetext{
* Investigadora del Instituto de Investigaciones Sociales, UABC.
} 
de entrega de la cosecha de parte del productor; es decir, mediante contratos de producción.

Existen claras diferencias en los contratos que se presentan entre ambos sectores. En el caso de procesamiento, se da mediante inversion extranjera directa (IED) de grandes corporaciones agroindustriales. Tradicionalmente se ha caracterizado por una producción destinada a mercado interno, con fuerte impacto en el consumo alimentario nacional, y por localizarse predominantemente en zonas agrícolas de la región de El Bajío que, además de contar con condiciones geoclimáticas y de infraestructura adecuadas, se encuentran cercanas a las grandes concentraciones urbanas en el centro del país.

En el caso de la producción de hortalizas frescas con IE, suponemos que los contratos presentan otras determinaciones. Ésta surgio desde principios del siglo en el estado de Sinaloa, por el interés de agricultores californianos de generar una oferta para cubrir la demanda de tomate en invierno y primavera temprana, temporada en la que, por razones climáticas, no podía producirse en California. Es producción para consumo en fresco destinada al mercado externo, principalmente estadounidense y tradicionalmente se ha localizado en la región noroeste del país, en zonas agrícolas que han presentado una mayor orientación exportadora y con agricultores que se han caracterizado por una mayor disponibilidad de recursos, sobre todo en tierra, agua y maquinaria agrícola (ver cuadro 1).

\section{CUADRO 1. México: estructura de las exportaciones de hortalizas, estados del noroeste y otros estados* (promedios anua- les).}

\begin{tabular}{|c|c|c|c|c|c|c|c|}
\hline & $\begin{array}{c}1970-72 \\
\%\end{array}$ & $\begin{array}{c}1973-75 \\
\%\end{array}$ & $\begin{array}{c}1976-78 \\
\%\end{array}$ & $\begin{array}{c}1979-81 \\
\%\end{array}$ & $\begin{array}{c}1982-84 \\
\%\end{array}$ & $\begin{array}{c}1985-87 \\
\%\end{array}$ & $\begin{array}{c}1988-90 \\
\%\end{array}$ \\
\hline Noroeste & 69.0 & 66.3 & 71.2 & 69.5 & 69.0 & 71.5 & 69.6 \\
\hline Baja Calif. & 1.9 & 4.2 & 4.8 & 6.0 & 9.5 & 12.1 & 11.7 \\
\hline Sinaloa & 60.7 & 57.3 & 62.3 & 59.1 & 53.0 & 51.0 & 44.9 \\
\hline Sonora & 6.4 & 4.9 & 4.0 & 4.3 & 6.4 & 8.4 & 13.0 \\
\hline Otros edos. & 31.0 & 33.7 & 28.8 & 30.5 & 31.0 & 28.5 & 30.4 \\
\hline México & 100.0 & 100.0 & 100.0 & 100.0 & 100.0 & 100.0 & 100.0 \\
\hline
\end{tabular}

FUENTE: Lós datos se calcularon con estadísticas anuales de exportaciones por producto y estado, en el Boletín Anual de la Confederación Nacional de Productores de Hortalizas, para los 21 años comprendidos.

* Datos referidos a volumen de las exportaciones; incluyen 50 hortalizas diferentes más el renglón de otros. 
En este caso el capital externo ha sido capital agrocomercial, constituido por compañías distríbuidoras de productos frescos localizadas en la frontera sur de Estados Unidos. Originalmente, las compañfas "pioneras" eran propiedad de agricultores californianos productores de hortalizas, con actividades que comprendían desde el cultivo hasta la comercialización (growing, packing, shipping \& marketing); sin embargo, desde los setenta, adquieren presencia significativa companffas distribuidoras propiedad de no-agricultores, no integradas directamente a la producción agrícola, dedicadas sólo a actividades de comercialización (shipping \& marketing).

Estas compañfas, por su localización fuera del territorio nacional, presentan menor integracion —comparada con la de los complejos de productos procesados - hacia la producción agrícola; y por su relativa dispersion, presentan menor integracion hacia el mercado ya que la distancia entre estas compañfas distribuidoras y los consumidores finales en el mercado estadounidense se encuentra aún fuertemente intermediada. The Red Book, publicación anual sobre la situación financiera y comercial de las compañías distribuidoras de hortalizas en Estados Unidos, para 1990 registra alrededor de trecientas y doscientas companfías cuyas oficinas principales se encuentran en California y Arizona, respectivamente.

Por otro lado, ante el impacto de la recesión y la caída de la demanda interna en la década de los ochenta, las corporaciones agroindustriales reorientaron su actividad incrementando la exportación de productos frescos, que ya realizaban de manera muy marginal desde los setenta; además de que incrementaron significativamente su producción semiprocesada y de productos congelados con destino al mercado externo. Al mismo tiempo, han presentado una ligera desconcentración geográfica, desde el centro del país hacia el noreste y noroeste, principalmente. Sin embargo, a principios de los noventa las exportaciones de hortalizas para consumo fresco en las principales zonas productoras del noroeste son todavía realizadas, en su mayoría, a través de contratos de producción con compañías distribuidoras estadounidenses.

Estos contratos de producción se basan en que el productor del norte de México, especialmente del noroeste, se compromete a entregar a la compañía distribuidora cierta producción que reúna las características —en cantidades, calidades y tiempo- establecidas por ésta última; y la compañía, localizada en los estados de la frontera sur estadounidense, particularmente de California y Arizona, se compromete a financiar la producción en alguna medida y a comercializarla de alguna manera (Stamatis, 1990:20). 


\section{LOS PRODUCTORES DE HORTALIZAS EN EL VALLE DE MEXICALI}

En el valle de Mexicali, con la caída de la producción algodonera y la diversificación del patrón de cultivos, se inicia en los años setenta el crecimiento de la producción de hortalizas para abastecer, por un lado, a distribuidores localizados en California y Arizona y, por otro, a distribuidores de la Ciudad de México ${ }^{1}$

Para fines de la década de los ochenta la producción de hortalizas represento, aproximadamente, al $1.5 \%$ de los productores, el $5 \%$ de la tierra y el agua, el $25 \%$ del valor de la produccion, a precio medio rural, y el $34 \%$ de la ocupación agrícola - sin considerar etapas poscosecha- respecto a los totales de la producción agrícola del valle; ${ }^{2}$ y, prácticamente toda la producción se destina a consumo fresco ${ }^{3}$ y para exportacion. ${ }^{4}$ Las condiciones de la demanda estadounidense frente a las de la demanda nacional, y los problemas de la horticultura californiana ${ }^{5}$ incidieron en un mayor dinamismo de la produccion para exportacion. ${ }^{6}$

Sin embargo, el sistema de hortalizas en el valle no es homogéneo e involucra tipos de productores claramente diferenciados. Para definir el tipo de productor, partimos de una caracterización de los productores de hortalizas del valle de Mexicali (ver cuadro 2) basada en variables sobre el comportamiento productivo en general, algunas de las cuales se describen a continuacion:

Los pequeños productores de hortalizas constituyen el $93 \%$ de las unidades de producción y $56 \%$ del total de productores; no presentan diversificacion ya que cultivan sólo una especie hortícola (melón tardío), cuentan únicamente

1 La superficie cultivada de hortalizas pasa de 1,200 ha. en 1970 a 15 mil en 1989 , que representa respectivamente $0.8 \%$ y $9 \%$ del total de superficie cultivada en el valle de Mexicali.

Estimados a partir de información de diversas dependencias de la Secretaría de Agricultura y Recursos Hidráhulicos (SARH) en Mexicali, B.C.

Durante los años ochenta se destinaron pequeños excedentes de melón a una enlatadora de jugos, y el $2 \%$ de la producción de espárrago a una enlatadora, ambas localizadas en el yalle.

4 Se exporta el $100 \%$ de la producción de espárrago, el $98 \%$ de cebollín, rábano y ajo, el $75 \%$ de la producción de lechuga, sólo la producción de melón se destina totalmente a mercado interno; el resto de la producción hortícola se destina al menos en un $90 \%$ a la exportación. (Estimaciones hechas a partir de información de campo y de datos de los movimientos de productos agropecuarios de la SARH en la localidad).

La producción de hortalizas en California enfrentó serios problemas laborales durante la primera mitad de la década de los setenta, además de que enfrenta un grave proceso de encarecimiento en los costos de producción, en especial en tierra y agua.

Del total de la superficie hortícola, la destinada a mercado nacional representó aproximadamente un $25 \%$ en 1970 , y aproximadamente un $8 \%$ en 1988. El resto es superficie orientada a mercado externo. 
CUADRO 2. Valle de Mexicali: algunas características del comportamiento productivo por tipo de productores de hortalizas. ${ }^{\text {a }}$

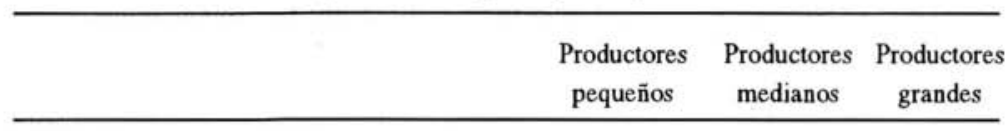

Número de unidades de produccion ${ }^{\mathrm{b}}$ 193.0

Número de productores ${ }^{c}$

Tipo de cultivo principal predominante
D.M.N. $^{d}$
o.M.E. ${ }^{\mathrm{e}}$
D.M.E. ${ }^{\mathrm{f}}$

Diversificación del patrón de cultivos hortícola ${ }^{\mathrm{g}}$ 1 especie 2-5 especies 6-10 especies hortícola hortícolas hortícolas

Participación en la superficie hortícola total ${ }^{\mathrm{h}}$

Superficie hortícola media por productor 4.5 ha. $\quad 25.0$ ha. $\quad 102.0$ ha. Superficie hortícola media por unidad de producción 4.5 ha. 235.0 ha. 1151.0 ha.

Participación en la superficie agrícola $^{i}$

Superficie agrícola media por productor 18.2 ha. $\quad 48.5$ ha $\quad 155.4$ ha. Superficie agrícola media por unidad de producción 18.2 ha. $\quad 455.9$ ha. 1753.8 ha.

FUENTE: Proyecto “Estructura agraria de Imperial y Mexiali”. IIS-UABC, 1987.

${ }^{\text {a }}$ Con resultados de la encuesta a productores de hortalizas en el valle de Mexicali, 1987, que incluyó a 267 de un listado de 287 productores, prácticamente el total de los hortaliceros en el valle (Stamatis, 1991).

${ }^{b}$ Con respecto de 174 unidades

${ }^{c}$ Respecto de 267 productores

${ }^{\mathrm{d}}$ Destinado a mercado nacional

${ }^{\mathrm{e}}$ Orientado a mercado externo

${ }^{\mathrm{f}}$ Destinado a mercado externo

${ }^{\mathrm{g}} \mathrm{Al}$ menos el $90 \%$ de los productores de cada tipo están dentro de cada categoría

${ }^{\text {h }}$ Respecto de 9,962 ha.

${ }^{i}$ Respecto de las 17,504 ha. que los productores de hortalizas cultivan con hortalizas y con otros cultivos no hortícolas. 
con el $6.5 \%$ de la superficie hortícola del valle y cultivan en promedio 4.5 ha. por unidad de producción y por productor; su producción hortícola está destinada en su totalidad al mercado interno, casi toda a mercado nacional.

Los medianos productores de hortalizas son el $16 \%$ de los productores y el $3 \%$ de las unidades de produccion; presentan como cultivo hortícola principal uno orientado a mercado externo (lechuga, melón temprano o sandía) y se caracterizan por producir de dos a cinco especies hortícolas diferentes; cultivan el $12.0 \%$ de la superficie hortícola con 48.5 ha. promedio por unidad de produccion.

Los grandes productores de hortalizas representan el $27.5 \%$ del total de productores de hortalizas y sólo el $4 \%$ de las unidades de producción; tienen como cultivo hortícola principal uno destinado a mercado externo (cebollín, espárrago, ajo), presentan una elevada diversificación de cultivos, de 6 a 10 especies hortícolas diferentes por unidad de producción; cultivan el $81 \%$ de la superficie hortícola del valle, con un promedio de $1,151.0$ ha. por unidad de producccion.

Así, el $4 \%$ de estas empresas de productores ${ }^{7}$ controlan el cultivo de más del $80 \%$ de la superficie hortícola, casi el $90 \%$ de la superficie cultivada para exportación y seguramente más del volumen ${ }^{8}$ canalizado a la compañía distribuidora para su venta en Estados Unidos, principalmente. Además, concentran, aunque en menor medida, la producción de otros cultivos no hortícolas, al contar con una superficie total cultivada de 1,754 ha. por unidad de producción.

Mientras que el 3\% de las empresas, unidades medianas, cultivan e! $12.0 \%$ de la superficie de hortalizas, cuya produccion se destina preferentemente a mercado externo y alrededor de la tercera parte a mercado interno, de forma principal a mercados regionales. Estas unidades cuentan en promedio con 235 ha. de hortalizas y 456 ha. cultivadas tanto con hortalizas como con otros cultivos.

Y por otro lado, el 93\% de las unidades de producción cultivan sólo el $7.0 \%$ de la superficie hortícola cuya producción se destina completamente a mercado interno, casi totalmente nacional. Para la gran mayoría de estos pequeños productores, la producción de hortalizas es un complemento a la producción en otros cultivos, ${ }^{9}$ en especial trigo y algodón, contando con 18 ha. promedio de superficie total cultivada.

7 En el total de casos, esas empresas se constituyen como grupos de productores aunque la tercera parte de esos grupos son miembros de una familia.

8 El volumen es mayor por los mayores rendimientos por hectárea que tienen por el uso más intensivo de capital.

El patrón de cultivos de los medianos y grandes productores incluye cultivos no hortícolas, en menor número de productores pero en considerablemente mayor extensión de superficie. 
Los años de experiencia productiva están en gran medida asociados al tamaño de la empresa hortícola (ver cuadro 3 ).

\section{CUADRO 3. Valle de Mexicali: años de experiencia productiva de los productores de hortalizas.*}

\begin{tabular}{lccc}
\hline & $\begin{array}{c}\text { Productores } \\
\text { pequeños } \\
\%\end{array}$ & $\begin{array}{c}\text { Productores } \\
\text { medianos } \\
\%\end{array}$ & $\begin{array}{c}\text { Productores } \\
\text { grandes } \\
\%\end{array}$ \\
\hline De 4 a 10 años & 77.0 & 100.0 & 16.0 \\
De 11 a 20 años & 23.0 & 0.0 & 50.0 \\
De 21 a 28 años & 0.0 & 0.0 & 34.0 \\
Total & 100.0 & 100.0 & 100.0 \\
\hline
\end{tabular}

FUENTE: Proyecto "Producción de hortalizas mexicanas para el mercado norteamericano". IIS-UABC, 1989.

* La información de este cuadro y los siguientes se obtuvo de la encuesta sobre contratos de producción de hortalizas en el valle de Mexicali, a una muestra de 23 productores de hortalizas, en 1989.

Todos los productores medianos tienen, en el momento de levantamiento de la información, entre 4 y 10 años produciendo hortalizas, mientras que la mitad de las grandes tienen entre 11 y 20 años y más de la tercera parte, entre 21 y 28 años. Salvo los productores medianos, los demás productores iniciaron su actividad orientados al mismo mercado, externo y nacional, para el que estaban produciendo. Esto nos revela las dificultades, por falta de contactos y recursos, de los pequeños productores para incursionar en el mercado externo y, por otro lado, lo poco atractivo que para los grandes productores resulta el mercado nacional. ${ }^{10}$

Por otra parte, los productores que iniciaron hace más de 20 años, todos constituidos en empresas grandes, lo hicieron en un periodo - fines de los affos cincuenta a mediados de los sesenta- en que la agricultura del valle se encontraba en bonanza con el monocultivo algodonero. Esta incursión

${ }^{10}$ A diferencia de la mayoría de los cultivos hortícolas en el valle, la producción para mercado nacional - melón tardío-, hasta fines de la década de los ochenta, estuvo sujeta a programas de siembra y de comercialización - con la intención de controlar la sobreproducción- en función de cuotas asignadas a las diferentes zonas productoras del país; con menores costos y normas de calidad menos estrictas que las de exportación, se caracterizó por estar más competida, en el sentido de incorporar un mayor número de productores con superficies muy reducidas y estar constantemente presionada por productores ocasionales que generaban producción al margen de la programación. 
temprana en la actividad está relacionada, en alguna medida, con los débiles intentos de diversificacion que se dieron en la segunda mitad de los años cincuenta, derivados de la reducción del agua para riego destinada al valle desde el sistema de presas del Río Colorado, en territorio estadounidense y, de una coyuntura de bajos precios del algodon, por el dumping que Estados Unidos provoco 6 en el mercado mundial de la fibra para esos años.

Los que iniciaron en el segundo periodo, de mediados de los sesenta a mediados de los setenta, incursionaron en una etapa de grandes cambios en el patrón regional de cultivos. Es decir, en medio de un acelerado proceso de diversificación que fue la respuesta a la aguda crisis de la producción agrícola regional, a la caída de la demanda y los precios que redujeron drásticamente la superficie dedicada al algodón.

Los que empezaron a producir hortalizas desde fines de los setenta -el $65 \%$ del total de productores-, lo hicieron en el periodo de mayor dinamismo de la producción hortícola regional. Desde entonces hasta fines de los ochenta, ésta creció un 10\% por encima de la producción agrícola regional y a un $8 \%$ más que la producción hortícola nacional, salvo por los años de 1980 a 1982, en que presenta tasas de crecimiento negativas por el impacto de la recesion económica estadounidense y la sobrevaluación del tipo de cambio (Stamatis, 1993:28).

La mayoría de los productores grandes (ver cuadro 4) destina su producción casi totalmente a mercado externo; mientras que la mayoría de los medianos destina entre un 40 a $80 \%$ a ese mercado; los pequeños productores destinan el $100 \%$ a mercado interno, y de éste, al menos el $90 \%$ a mercado nacional. En todos los casos, las otras proporciones de la produccion son destinadas a mercados regionales.

\section{CUADRO 4. Valle de Mexicali: destino de la producción por tipo de productores de hortalizas.}

\begin{tabular}{lrrr}
\hline Destino de la produccion & $\begin{array}{c}\text { Productores } \\
\text { pequeños } \\
\%\end{array}$ & $\begin{array}{c}\text { Productores } \\
\text { medianos } \\
\%\end{array}$ & $\begin{array}{c}\text { Productores } \\
\text { grandes }\end{array}$ \\
\hline 95-100\% a mercado externo & 0.0 & 25.0 & 67.0 \\
$\begin{array}{l}\text { 40-80\% a mercado externo } \\
90-100 \% \text { a mercado nacional }\end{array}$ & 0.0 & 75.0 & 33.0 \\
Total & 100.0 & 0.0 & 0.0 \\
\hline
\end{tabular}

FUENTE: Proyecto "Producción de hortalizas mexicanas para el mercado norteamericano". IIS-UABC, 1989. 
Además de las dificultades que tienen para incursionar con éxito en el mercado externo, ${ }^{11}$ los pequeños productores tienen serias limitaciones para crecer en su mercado tradicional. Por el hecho de encontrarse en una zona predominantemente exportadora, la producción para mercado interno presenta serias desventajas, sobre todo ante factores escasos como lo ha sido por tradición la fuerza de trabajo agrícola y, recientemente, el agua para riego. Entre la producción hortícola para mercado externo y la producción hortícola para mercado interno se establece una competencia por estos factores productivos, en condiciones de precios desfavorables para esta última.

\section{EL CAPITAL EXTRANJERO Y LOS CONTRATOS DE PRODUC- CIÓN DE HORTALIZAS EN EL VALLE DE MEXICALI}

La producción regional de hortalizas para exportación presenta diferentes formas de organización en lo que se refiere a la relacion entre el productor regional con el capital externo. En este aspecto, los contratos de producción han sido la forma fundamental por diversas razones.

Además del interés de las compañías distribuidoras californianas de crear fuentes de abastecimiento ante una demanda mayor que la oferta doméstica en el mercado estadounidense, las hortalizas requieren fuertes inversiones ${ }^{12}$ y no se cont 6 con líneas de crédito interno para su produccion agrícola hasta mediados de los ochenta; a partir de entonces, mediante el programa de Fira-Bancomext, se abrieron líneas de crédito para hortalizas que los productores del valle de Mexicali no empezaron a utilizar sino hasta fines de la misma década, debido a que esas líneas financiaban actividades de cosecha y poscosecha, para las cuales los productores tenían mayores facilidades de financiamiento de parte de las compañías distribuidoras. Las hortalizas implican altos riesgos de comercialización, ya que son los productos agrícolas mayormente perecederos, es decir, su vida aproximada para consumo fresco no excede, en la mayoría de los casos, a las dos semanas, ${ }^{13}$ por lo que requieren de una rápida y eficiente comercialización.

${ }^{11}$ El único cultivo hortícola que realizan este tipo de productores es el de melón tardío, que se cosecha durante los meses de octubre y noviembre, por lo que, tomando en cuenta sus condiciones productivas, les está vedada su exportación debido al elevado arancel, de $35 \%$ ad valorem, en el mercado estadounidense. Hay casos de estos productores que han realizado intentos por exportar, que resultaron fallidos.

${ }_{12}$ Las hortalizas son los productos agrícolas que presentan los costos de producción más altos por hectárea cultivada; en el valle de Mexicali esos costos son de 4 a 6 veces más altos que el algodón y de 8 a 12 veces más altos que el trigo.

${ }^{13}$ Las hortalizas son productos altamente perecederos, incluso respecto de los demás productos agrícolas; su vida aproximada para consumo fresco no excede, en la mayoría de los casos, a las dos semanas después de ser cosechados. En este caso se encuentran cebollín, 
La zona agrícola del valle presenta condiciones propicias que le han permitido adecuarse a los requerimientos de la producción de hortalizas de exportación. Por un lado, cuenta con recursos productivos, en especial con la capacidad de ejercer un efectivo control del riego; no sólo porque hay agua disponible cuando se requiere sino también porque, debido a la escasa precipitación pluvial que caracteriza a la zona, no hay posibilidades de lluvia y se puede evitar el agua en momentos en que causaría graves daños a los cultivos. ${ }^{14}$ Y por otro lado, es una zona agrícola tradicionalmente orientada hacia mercado externo por lo que cuenta con agricultores con experiencia productiva en cultivos muy comerciales. Debido a una producción agrícola basada más en la incorporación de recursos técnicos que en el uso de recursos naturales, los altos costos de producir en el valle de alguna manera han provocado que los productores se orienten -en la medida en que las limitaciones, que no son pocas, se los permiten- a cultivos que permitan mayores niveles de rentabilidad, es decir, a cultivos de exportacion.

Aunado a las razones anteriores está el hecho de que, todos los productores del valle de Mexicali que destinan su produccion a la exportación, no tienen capacidad de distribución en el mercado estadounidense, ni en otros mercados externos, y dependen de una compañía estadounidense para comercializar su producción. Por lo que, en resumen, se considera que la producción de hortalizas de exportación en el valle de Mexicali, desde su surgimiento a principios de los sesenta hasta fines de los años ochenta, se ha basado en los contratos de producción.

Y un contrato de producción, además de un contrato de compra-venta entre productor y distribuidor, implica necesariamente relaciones "hacia atrás", a nivel de la producción agrícola. Es decir, supone integración a nivel de la producción y no una simple relación comercial.

En cuanto a hasta qué punto podemos afirmar la existencia de contratos de producción en la exportación de hortalizas frescas, consideramos como condición fundamental la presencia de flujos de servicios financieros y/o de insumos de la compañía extranjera hacia al agricultor mexicano y el flujo de productos de este último hacia la primera.

ejote, espinacas, rábano, lechuga, pepinos y tomate entre otros. Por lo que deben ser consumidas, o en su caso industrializadas, casi inmediatamente después de la cosecha. Por ello requieren de una rápida comercialización y su producción debe responder a una programación que permita cierto control sobre los volúmenes y las fechas de cosecha.

14 Las hortalizas son especialmente susceptibles a las enfermedades fungosas que provoca el exceso de humedad, sobre todo tomando en cuenta las estrictas normas de calidad que exige el mercado externo. 
De los productores de hortalizas en el valle de Mexicali, ${ }^{15}$ la mayorfa de las empresas grandes y la mitad de las medianas reciben insumos del distribuidor (ver cuadro 5). Estos insumos están constituidos mayormente por semilla y material de empaque.

A su vez, la mayoría de los productores medianos y todos los productores grandes reciben algún financiamiento de la compañfa distribuidora (ver cuadro 6).

CUADRO 5. Valle de Mexicali: flujo de insumos de la compañía distribuidora extranjera a los productores de hortalizas (porcentajes).

\begin{tabular}{lcc}
\hline & $\begin{array}{c}\text { Productores } \\
\text { medianos }\end{array}$ & $\begin{array}{c}\text { Productores } \\
\text { grandes }\end{array}$ \\
\hline No se presenta & 50.0 & 16.5 \\
Sí se presenta & 50.0 & 83.5 \\
Total & 100.0 & 100.0 \\
\hline
\end{tabular}

FUENTE: Proyecto "Producción de hortalizas mexicanas para el mercado norteamericano". IIS-UABC, 1989.

CUADRO 6. Valle de Mexicali: flujo de servicios financieros de la compañía distribuidora extranjera a los productores de hortalizas (porcentajes).

\begin{tabular}{lcc}
\hline & $\begin{array}{c}\text { Productores } \\
\text { medianos }\end{array}$ & $\begin{array}{c}\text { Productores } \\
\text { grandes }\end{array}$ \\
\hline No se presenta & 25.0 & 0.0 \\
Sí se presenta & 75.0 & 100.0 \\
Total & 100.0 & 100.0 \\
\hline
\end{tabular}

FUENTE: Proyecto "Producción de hortalizas mexicanas para el mercado norteamericano". IIS-UABC, 1989.

15 A partir de aquí consideramos sólo a los medianos y grandes productores de hortalizas, puesto que los pequeños productores no exportan. 
Este financiamiento se da mediante la disposición de dinero en efectivo - por deposito bancario- para el productor, por el que la companfa aparenta no cobrar ningún interés aunque el costo de ese dinero lo carga de otra manera al productor. Esta modalidad era más común en los primeros años de la actividad; al parecer, a partir de los años setenta y sobre todo de los ochenta, es cada vez más frecuente que la compañía distribuidora simplemente otorgue la firma de aval para el crédito que el productor gestiona ante un banco en California.

Así, cumplen la condición necesaria de ser receptores de financiamiento monetario y/o insumos, todos los productores que exportan (ver cuadro 7).

CUADRO 7. Valle de Mexicali: flujo de servicios financieros y/o insumos de la compañía distribuidora extranjera a los productores de hortalizas (porcentajes).

\begin{tabular}{lcc}
\hline & $\begin{array}{c}\text { Productores } \\
\text { medianos }\end{array}$ & $\begin{array}{c}\text { Productores } \\
\text { grandes }\end{array}$ \\
\hline $\begin{array}{l}\text { Financiamiento } \\
\text { e insumos }\end{array}$ & 50.0 & 83.0 \\
Financiamiento & 25.0 & 17.0 \\
Insumos & 25.0 & 0.0 \\
Total & 100.0 & 100.0 \\
\hline
\end{tabular}

FUENTE: Proyecto "Producción de hortalizas mexicanas para el mercado norteamericano". IIS-UABC, 1989.

Por otro lado, los servicios financieros incluidos en todas las modalidades de contratos de producción -incluso en los que implican IED de corporaciones agroindustriales - son siempre financiamientos parciales; y lo mismo los flujos de insumos.

Los contratos con compañías distribuidoras suponen que el productor recibirá su pago una vez que esas compañías han vendido la producción, para lo cual deberían tener un mes de plazo después de que el productor ha entregado al distribuidor.

Ese plazo está contemplado en el Fideicomiso del PACA (PACA Trust) como parte de la Ley PACA (Perishable Agricultural Commodity Act), que es la que regula las relaciones entre los productores de hortalizas y los diferentes agentes comercializadores en Estados Unidos (Ley PACA, 1986). 
Esta ley incluye la regulación no sólo de la producción doméstica sino también la proveniente de otros países, y con ella los exportadores mexicanos han intentado regular su actividad. Sin embargo, no es poco frecuente que estos productores mexicanos señalen el incumplimiento en los plazos que pactaron con la distribuidora.

Ese pago son los ingresos netos del productor una vez hecha "la liquidación", es decir, de que la distribuidora le hace cuentas al productor con base en las facturas de venta, y le cobra el financiamiento, los insumos que le proporcionó y la comisión de un 10 a $15 \%$ del valor de las ventas por el servicio de comercialización.

La subfacturación de las ventas parece ser una práctica generalizada de las compañías distribuidoras hacia los productores mexicanos, por lo que es aquí donde la compañía le cobra al productor los costos del financiamiento que le proporciono.

\section{CUADRO 8. Valle de Mexicali: tipo de financiamiento que reciben los productores de hortalizas de la compañía distribui- dora extranjera (porcentajes).}

\begin{tabular}{lcc}
\hline & $\begin{array}{c}\text { Productores } \\
\text { medianos }\end{array}$ & $\begin{array}{c}\text { Productores } \\
\text { grandes }\end{array}$ \\
\hline Financiamiento a la venta & 50.0 & 0.0 \\
Cosecha hasta centro de distribucion & 25.0 & 50.0 \\
30\%-50\% costos totales & 25.0 & 50.0 \\
Total & 100.0 & 100.0 \\
\hline
\end{tabular}

FUENTE: Proyecto "Producción de hortalizas mexicanas para el mercado norteamericano". IIS-UABC, 1989.

La mitad de las empresas medianas recibe financiamiento a la venta como modalidad de los servicios financieros proporcionados por la distribuidora (ver cuadro 8). Esta modalidad, que en este caso incluye el suministro de algunos insumos como aportación a los gastos de producción, se refiere al pago de la producción empacada en el momento de la entrega del productor al distribuidor, con base en un precio fijo o bien a un precio mínimo libre al alza. Este financiamiento a la venta es un servicio financiero y no el pago por ventas, porque este pago tiene que hacerse una vez que la distribuidora ha vendido la producción, para lo que, como 
vimos, tiene un mes de plazo. Aunque el financiamiento a la venta parece ser más desventajosa para el productor que las otras modalidades, por el hecho que éste no recibe el recurso en ningún momento de la producción, en opinion de los mismos productores resulta ser un arreglo conveniente a sus necesidades.

La cuarta parte de las medianas empresas exportadoras y la mitad de las grandes reciben un financiamiento que cubre entre un 30 y $50 \%$ de los costos totales de produccion, es decir, desde las actividades previas a la siembra hasta la entrega de la produccion empacada a la compañf́a distribuidora. La otra mitad de las grandes y la cuarta parte de las medianas, reciben ese financiamiento desde el inicio de la cosecha, incluyendo poscosecha, empaque y exportacion, o sea, una vez que ha cubierto con otros recursos las etapas de siembra, fertilización, control de plagas y enfermedades y otras previas a la cosecha. Esta última modalidad de servicios financieros puede suponer alrededor del $50 \%$ de los costos totales.

Si el flujo de servicios financieros y/o de insumos nos permite diferenciar la producción comercializada por contrato de la producción para mercados "abiertos", la presencia de esos servicios como financiamientos parciales es un indicador que nos permite distinguir la producción contratada de la que implica inversión extranjera directa en la produccion agrícola (IED).

Por lo que, si anteriomente consideramos la presencia de flujos de financiamiento de la compañía al productor como condición necesaria, además de la entrega de la producción de éste a la primera; en este punto podemos señalar que, consideramos la presencia de esos flujos en términos de financiamientos parciales como condición suficiente para definir la existencia de contratos de producción en la producción de hortalizas de exportación. Y como vimos, en todos los casos los financiamientos de la distribuidora al productor son parciales.

Para poscosecha, los productores declararon recurrir a líneas de crédito de instituciones mexicanas destinadas a apoyar la actividad industrial; y para producción agrícola, sólo las medianas empresas declaráron haber utilizado recursos de FIRA, banca de segundo piso de apoyo a la agricultura; mientras que todos los productores grandes declararon financiarlas con recursos propios, provenientes tanto de la exportación de hortalizas como de otras actividades económicas.

Además de contar con el canal de comercialización implícito en el contrato de producción, único o principal, que mantienen con "la" compañía distribuidora, los productores locales cuentan con otros canales paralelos a la producción contratada (ver cuadro 9). 
CUADRO 9. Valle de Mexicali: nivel de disponibilidad de canales de comercialización para mercado externo/productores de hortalizas.

\begin{tabular}{lrc}
\hline & $\begin{array}{c}\text { Productores } \\
\text { medianos }\end{array}$ & $\begin{array}{c}\text { Productores } \\
\text { grandes }\end{array}$ \\
\hline 1 Cía. Dist. & 50.0 & 16.5 \\
1 Cía. Dist. y 1 Broker & 50.0 & 67.0 \\
Más de 1 Cía. Dist. y 1 Broker & 0.0 & 16.5 \\
Total & 100.0 & 100.0 \\
\hline
\end{tabular}

FUENTE: Proyecto "Producción de hortalizas mexicanas para el mercado norteamericano". IIS-UABC, 1989.

La mitad de los productores medianos y la mayoría de los grandes declararon contar además con los servicios de un broker, que es un agente intermediario entre el productor local y una compañía distribuidora o entre ésta y una cadena de tiendas en Estados Unidos.

La diferencia entre este personaje y la compañfa es que esta última cuenta con infraestructura de comercialización - bodegas y transporte refrigerado-que le permiten prestar los servicios de distribución, además de los servicios de intermediación con los que sí cuenta el broker y en los que suele ser más eficiente. De acuerdo con las leyes estadounidenses, para que una compañía distribuidora pueda incluir además los servicios de intermediación o "brokerage", requiere de una licencia especial aparte de la licencia de "dealer" que implica la distribución (Ley PACA, 1986:16-18).

Los servicios del broker no incluyen el suministro de financiamiento y/o insumos, la producción se canaliza hacia mercados "abiertos" y la relación con el productor se da simplemente a través de contratos de compra-venta. Esta forma de comercializacion, aunque implica mayores riesgos para el productor, mayor inseguridad en los precios y menor compromiso del intermediario, coyunturalmente puede significar mejores precios que los que puede obtener con la producción contratada. Parece ser que por ello, entre otros factores, la producción para mercados abiertos requiere del relativo margen de seguridad que aportan los contratos de producción. Es decir, el que se dé la primera supone en gran medida la presencia de producción contratada.

Para definir el grado de integración de los productores de hortalizas en el valle de Mexicali, consideramos como indicadores el lugar o la etapa 
del proceso en la que estos entregan su producción a la compañía distribuidora y el tipo de infraestructura de comercialización con la que cuentan.

En este problema de integracion hacia el mercado de los productores de hortalizas de exportación en el noroeste de México, se encuentran desde productores que entregan la producción sin empacar, los que la entregan libre a bordo ( $\mathrm{LAB}$ ) en empaque, los que la entregan LAB en frontera, los que la entregan en las instalaciones de la compañía distribuidora -en California y Arizona-, hasta productores que cuentan con servicios e rfraestructura de distribución en el sur de Estados Unidos.

\section{CUADRO 10. Valle de Mexicali: etapa de entrega de la producción de hortalizas a la compañía distribuidora extranjera (porcentajes).}

\begin{tabular}{lrc}
\hline & $\begin{array}{c}\text { Productores } \\
\text { medianos }\end{array}$ & $\begin{array}{c}\text { Productores } \\
\text { grandes }\end{array}$ \\
\hline En campo o empaque & 0.0 & 0.0 \\
LAB en empaque & 50.0 & 0.0 \\
LAB en frontera & 50.0 & 16.5 \\
En cia. distribuidora & 0.0 & 83.5 \\
Con distribuidora propia & 0.0 & 0.0 \\
Total & 100.0 & 100.0 \\
\hline
\end{tabular}

FUENTE: Proyecto "Producción de hortalizas mexicanas para el mercado norteamericano". IS-UABC, 1989.

Al respecto encontramos que, mientras la mayoría de las empresas grandes entregan la producción contratada en las instalaciones de la companf́a distribuidora, localizadas en Caléxico, Holtville, Indio, Laine, Somertone y Salinas en el estado de California y en Yuma y Phoenix en el estado de Arizona; la mitad de las empresas medianas entrega LAB en frontera, una vez que pasa la aduana en Mexicali o en San Luis R.C., la companfía se hace cargo del transporte hasta las bodegas refrigeradas en el centro de distribución localizado también en los estados de California y Arizona; y la otra mitad la entrega $L A B$ en empaque, para que una vez empacada y estibada en el transporte a cargo de la compañfa sea trasladada a la aduana fronteriza y de ahr al centro de distribución (ver cuadro 10). 
Esto supone que la mayoría de las empresas grandes cuentan con infraestructura de refrigeración en la planta empacadora y con los servicios de transporte refrigerado, adecuado para la trayectoria completa hasta las instalaciones de la compañía distribuidora. Mientras que la mayoría de las empresas medianas tienen infraestructura de refrigeracion en el empaque $\mathrm{y}$ transporte no refrigerado.

Ninguna empresa exportadora de hortalizas en el valle cuenta con infraestructura y servicios de distribución propios en el mercado estadounidense. Entre los empresarios medianos, el nivel de integración es bajo, o sea que cuando más, entregan su producción LAB en frontera y cuentan sólo con infraestructura en transporte no refrigerado y refrigeración posempaque.

CUADRO 11. Valle de Mexicali: nivel de integración hacia delante de los productores de hortalizas (porcentajes).

\begin{tabular}{lcc}
\hline & $\begin{array}{c}\text { Productores } \\
\text { medianos }\end{array}$ & $\begin{array}{c}\text { Productores } \\
\text { grandes }\end{array}$ \\
\hline Muy bajo & 50.0 & 0.0 \\
Bajo & 50.0 & 16.5 \\
Medio & 0.0 & 83.5 \\
Alto & 0.0 & 0.0 \\
Total & 100.0 & 100.0 \\
\hline
\end{tabular}

FUENTE: Proyecto "Producción de hortalizas mexicanas para el mercado norteamericano". IIS-UABC, 1989.

Como resultado tenemos que, cuando más, los productores de hortalizas de exportación del valle de Mexicali presentan un nivel medio de integración hacia el mercado externo. Ninguna empresa local cuenta con infraestructura y servicios de distribución, lo que significa que no logran el nivel de integración más alto que presentan productores de hortalizas para consumo fresco en otras zonas del noroeste (ver cuadro 11).

En los valles de Culiacán, Guasave y el Carrizo, en el estado de Sinaloa, se encuentran los productores mexicanos que presentan, al contar con companfía distribuidora propia, el mayor nivel de integracion hacia el mercado estadounidense. Cierto que son las zonas tradicionales de producción de hortalizas frescas para exportación, con décadas en la actividad. ${ }^{16}$ 
Por otro lado, algunas empresas de la zona de la costa de Ensenada, en el mismo estado de Baja California, y una empresa del valle de San Luis R.C., Sonora - que está integrado físicamente al valle de Mexicalipresentan un alto nivel de integración. Ambas zonas se incorporaron recientemente a la actividad, casi al mismo tiempo que el valle de Mexicali, varios años antes la primera y un poco después, aunque con mayor dinamismo, la segunda.

Sin embargo, en todos los casos de esas zonas que han logrado un nivel de integración alto, los productores con ese nivel representan una minoría respecto del total de productores que exportan. Y además, es una integración hacia el mercado externo muy relativa, pues aunque cuentan con su propia compañía distribuidora siguen dependiendo en gran medida de otras compañfas distribuidoras y brokers con mayor capacidad de comercialización en el mercado estadounidense. Incluso, las exportaciones de gran parte de estos productores a Canadá, Europa y Japón se realizan con "triangulacion", es decir, son reexportadas desde Estados Unidos por esas companfías y brokers estadounidenses.

\section{A MANERA DE CONCLUSIONES .}

Entre producción hortícola y capital externo se presentan las más variadas combinaciones que se expresan en las diversas formas que adopta esa relación. En el valle de Mexicali, además de la producción por contrato, partes significativas de la produccion se realizan mediante otras formas de participación del capital extranjero.

Como vefamos, a través de la forma de "brokerage", una parte se comercializa en mercados abiertos; es esta una relación a nivel de la circulación y supone simplemente un acuerdo de intermediación, no financiamiento ni insumos hacia el productor.

En el valle se presentan nuevas formas de organización de la producción de hortalizas para mercado externo. Una de ellas es la maquila, que adquirio significativa presencia en la segunda mitad de la década de los ochenta; funciona bajo el régimen arancelario maquilador de importaciones temporales en la entrada de productos semiterminados, con exención del impuesto de importación a México, y la salida del producto terminado, con el impueșto sobre el valor agregado en su importación a Estados Unidos.

\footnotetext{
16 Se tienen antecedentes de la actividad en estas zonas, desde la primera década de este siglo; sin embargo, presenta un dinamismo significativo a partir de la segunda guerra y el periodo de posguerra. En Culiacán y en Guasave hay cuando menos dieciocho y siete grandes empresas, respectivamente, que presentan ese alto nivel de integración.
} 
En la forma de maquila, además de no haber control de la comercialización por parte del productor, como sucede en la producción de hortalizas de exportación en general, no hay una etapa de producción agrícola. La figura del productor regional es sustituida por la del empacador o maquilador. El "productor" regional se limita a la fase de empaque de hortalizas cosechadas en territorio estadounidense, que son las que pueden cosecharse con máquina, por lo que el empaque es la fase del proceso de producción donde se concentra la mayor demanda de mano de obra. En este caso se encuentra principalmente la producción de zanahoria del Valle Imperial.

Y la forma más incipiente en su versión moderna, ${ }^{17}$ diferente a la maquila y a los contratos en cualquier modalidad, es la que implica inversión extranjera directa (IED). En este caso, todas las fases de la actividad hortícola, incluyendo la producción agrícola, se realizan exclusivamente con recursos financieros externos y sin la más mínima injerencia de un productor local. En lugar de este último aparece un personaje similar a un corredor de bienes raices, para el arrendamiento de tierras, en su mayoría parcelas ejidales.

Esta forma de producción, además de eliminar la figura del "productor local" y sustituirla por la de una "corredor de bienes raíces", implica financiamiento externo completo con un abasto completo de insumos, por parte de la compañía distribuidora.

Puesto que hasta 1991, con las modificaciones al artículo 27 constitucional, supuestamente estaba prohibido el arrendamiento de tierras ejidales, el mecanismo que se utilizaba era la figura jurídica de los "contratos de asociación en participación". Esta figura aparece expresamente legislada, por primera vez, en la Ley de Fomento Agropecuario de 1980, con el supuesto de establecer facilidades de asociación entre ejidatarios y capital privado; su objetivo fue permitir el acceso de los empresarios agrícolas a las tierras irrigadas no incorporadas formalmente al mercado, por lo que esos contratos de asociación parecen haber sido diseñados precisamente como contratos de arrendamiento (Stamatis, 1991: 26).

En el valle de Mexicali, para el año de 1989, se encuentran establecidas al menos veinte plantas empacadoras de hortalizas frescas para exportación y una planta enlatadora de espárrago. Esta última, propiedad del grupo más fuerte de productores de hortalizas en el valle, producía bajo contrato para una agroindustria estadounidense el espárrago enlatado en salmuera destinado totalmente a la exportación.

${ }^{17}$ La IED fue una forma de participación del capital estadounidense para la producción de algodón en el valle de Mexicali, desde principios del siglo a fines de la década de los treinta (Stamatis, 1988). 
Todos los empaques, salvo uno, operaban bajo alguna modalidad de contrato de produccion, tres de ellos realizaban también actividades de maquila; $y$, el otro empaque operaba, de manera relativamente encubierta, bajo la forma de IED en la producción agrícola, con participación de capital japonés y estadounidense. $^{18}$

\section{BIBLIOGRAFÍA}

C.N.P.H., Boletín Anual, Temporadas 1969-1970 a 1989-1990, Confederación Nacional de Productores de Hortalizas, Culiacán, Sin., 1970 a 1990.

STAMATIS M., Martha. 1988. "El valle de Mexicali: agricultura e inversión extranjera (1901-1986).", Estudios Fronterizos, nos. 12-13, I.I.S.-UABC, Mexicali, B.C.

- 1990. "Hortalizas para USA", Ciudades, no. 5, enero-marzo, Red Nacional de Investigación Urbana, México, D.F.

- 1991. Agricultura e inversión extranjera en el valle de Mexicali: la producción de hortalizas de exportación, Tesis de Maestría, Universidad Autónoma Chapingo.

- 1993. "La evolución del patrón de cultivos en el valle de Mexicali: un análisis regional (1964-1987).", en Cuadernos de Ciencias Sociales, serie 4 , no. 11 , IIS-UABC.

U.N.P.H. (traducción y edición).1986. Ley PACA Decreto sobre Mercancías Agrícolas Perecederas de los Estados Unidos de América, Unión Nacional de Productores de Hortalizas, Culiacán, Sin.

${ }^{18} \mathrm{Al}$ parecer, la razón de localización de esta compañía es abastecer el mercado japonés reexportando la producción desde Estados Unidos. 